\title{
APROXIMACIONES AL CONTENIDO FILOSÓFICO POLÍTICO DE LA NOCIÓN DE INDIO EN DIEGO DE CASTRO TITU CUSI YUPANQUI (1570) Y FELIPE GUAMAN POMA DE AYALA (1615)*
}

\author{
APPROACHES TO THE NOTION OF INDIAN AND ITS POLITICAL \\ PHILOSOPHICAL CONTENT ON DIEGO DE CASTRO TITU CUSI YUPANQUI \\ (1570) AND FELIPE GUAMAN POMA DE AYALA (1615)
}

\author{
Alejandro Viveros Espinosa**
}

\begin{abstract}
Este escrito posiciona algunas aproximaciones respecto del contenido filosófico político presente en la noción de indio en los Andes coloniales mediante la interpretación de las crónicas mestizas de Titu Cusi Yupanqui (1570) y Felipe Guamán Poma de Ayala (1615). A partir de una problematización teórica relativa a la noción de indio como construcción discursiva creada durante el período colonial, cuestionaremos los modos de vectorización que dirigen una reflexión filosófico política. Para ello destacaremos sus propuestas con tres entradas, a saber, el inca como figura de autoridad política, los mecanismos de traducción cultural presentes en su producción escritural y la modernidad como horizonte de problematización filosófica. En suma, buscamos posicionar un ejercicio crítico acerca del sentido filosófico político de ambos textos, donde se configuran nuevos horizontes de pregunta relativos a la noción de indio.
\end{abstract}

Palabras claves: Indio, contenido filosófico político, Titu Cusi Yupanqui, Felipe Guamán Poma de Ayala.

This paper posits certain approaches towards the notion of Indian and its philosophical content through the interpretation of Titu Cusi Yupanqui (1570) y Felipe Guamán Poma de Ayala's (1615) chronicles. Following a theoretical questioning on the notion of Indian as a discursive construction created during the colonial period, we will remark some ways of vectorization in which both chronicles address a political philosophical reflection. We will remark their proposals following three issues, i.e., the Inca as political authority, the mechanisms of cultural translation on their written production, and the Modernity as philosophical horizon. In short, we seek for a critical exercise on a political philosophical level where the reflections about the notion of Indian open new questioning horizons.

Key words: Indian, political philosophical content, Titu Cusi Yupanqui, Felipe Guamán Poma de Ayala.

\section{Introducción}

La historiografía indiana ofrece un arco increíble de textos heterogéneos en perspectiva y elaboración verbal, que permiten análisis comparativos de diferente dimensión y objetivo. Si nos atrevemos a reconstruir el condicionamiento de la producción textual y a entrar en las complejas interrelaciones, podemos aprovechar plenamente estos textos fascinantes que todavía esconden muchas joyas para nosotros (Stoll 2010: 1281).

Este artículo busca desplegar una aproximación inicial hacia el contenido filosófico político presente en la noción de indio en los Andes coloniales (15701615) a partir del análisis e interpretación de dos “crónicas mestizas" (Lienhard 1983). Nos referimos a las célebres "Instrucción del Inca Don Diego Titu Cusi Yupanqui para el muy ilustre señor el Licenciado Lope García de Castro" (1570) de Diego de Castro Titu Cusi Yupanqui y "El Primer Nueva Corónica y Buen Gobierno" (1615) de Felipe Guamán Poma de Ayala. El ejercicio interpretativo acerca de las crónicas mestizas implica la comprensión de elementos directamente interrelacionados con la narración histórico literaria. Ahí buscaremos otros matices, otras señas, indicaciones claras que revelen niveles de enunciación ocultos en su construcción discursiva. Hablamos de un ejercicio teórico relativo a un discurso identitario en construcción, que contiene elementos filosófico políticos dispuestos a ser utilizados de forma no dogmática y abierta a nuevos horizontes ${ }^{1}$ de comprensión y pregunta.

* Resultado del proyecto CONICYT/FONDECYT Postdoctorado No 3140318.

** Universidad de Chile, Santiago, Chile. Correo electrónico: aviveros@u.uchile.cl 
Aquí es necesario aceptar a las crónicas mestizas como "textos culturales" (Bachmann-Medick 2006), precisamente porque permite -en términos metodológicos-interpretar textos escritos (alfabéticos) no solo como narraciones histórico literarias, sino también relevando los modos de acercamiento e interpretación que tensionan y resignifican sus contenidos mediante movimientos vectoriales (Ette 2013).

Sin embargo, el objetivo es analizar y problematizar aquello que nombramos como contenido filosófico político de un concepto complejo y difícil, a saber, la noción de indio en su construcción andina colonial. Los caminos para cuestionar la construcción discursiva respecto del indio son varios y distintos. Destacamos el esquema que propone Martínez (2007) a propósito de la categoría ${ }^{2}$ de indio en los Andes coloniales (siglo XVI), particularmente porque aclara los modos de descripción e interpretación que fueron utilizados en el contexto histórico cultural colonial latinoamericano. Los ya clásicos estereotipos del salvaje, bestia, bárbaro, infiel, pagano, oliváceo, etíope y similitudine homines en tanto que vehículos interpretativos de la naturaleza del indio, de su capacidad intelectiva y sus costumbres, se explican dentro de un proceso de jerarquización y homogeneización de la alteridad (heterogeneidad) de los seres humanos en el imaginario clasificatorio europeo del siglo XVI (Martínez 2007: 23-25). Recordemos que la clasificación (denominación, definición) de seres humanos es un ejercicio de poder que configura discursivamente nuevos sujetos o subjetividades, en este caso, por medio de la categoría de indio. En consecuencia, el ejercicio de invención del indio como concepto e identidad cultural es equivalente al ejercicio de invención hecho sobre América y lo americano (O'Gorman 2001). Bien sabemos que la categoría o noción de indio llega a los Andes como una subjetividad ya creada $^{3}$; en ella se distinguen algunos "momentos" de construcción discursiva referente a los indios y se reconocen dos tipos de discursividades concordantes con dos paradigmas culturales, uno devenido de la "semejanza" y otro de la "diferencia", y que posicionan el "gran modelo intelectual epistémico de Occidente" (Martínez 2007: 32). Hablamos de un conjunto de maneras de referir y construir una estructura de significación fundamental donde se distingue un "nosotros" y un "otro" (alteridad). En este sentido, el concepto de "etnificación" (Martínez 2007: 23) releva problemas filosóficos importantes como: la esclavitud natural, las reflexiones respecto de la condición humana del indio, o bien en el modelo explicativo relacionado con la historia natural (Martínez 2007; Pagden 1989). Aquí la etnificación (desde la semejanza o la diferencia) profundiza un ejercicio descriptivo que afecta a la clasificación de lo indio acontecida en los Andes coloniales. Acerca de ello, y desde una comprensión teórica, podemos atender la siguiente indicación:

$\mathrm{Si}$, por un lado, estos procedimientos son interesantes para entender ciertos mecanismos de semantización y etnificación, no se puede dejar de lado otro aspecto: el que cualquiera sean las discursividades a las que se acuda, todas ellas utilizaron las mismas prácticas culturales de los otros (un conjunto de signos relativamente reducido) para etnificarlos. El etnocentrismo implica imponer, de todas maneras, sus propias marcas significantes (visuales, auditivos, olfativos) y abarcar cualquier práctica cultural: instituciones sociales, prácticas políticas o sociales, uso de objetos y emblemas, etc. La significación está dada por una operación simple: es la sociedad que etnifica quien toma significante cualquiera de esas prácticas y lo hace por una operación de presencia-ausencia.

La performatividad de todos estos discursos y sus varias discursividades es evidente: a lo largo del siglo XVI se construyó, efectiva y eficazmente, ese nuevo sujeto social y cultural: el indio, con un rasgo esencial: que bajo condiciones de coacción o de asimilación, de desestructuración o de readecuaciones, fueron muchas las sociedades indígenas que aceptaron esa nueva condición y la incorporaron a un nuevo proceso de construcciones identitarias, así como otras siguieron manejando sus antiguas denominaciones (Martínez 2007: 34).

Siguiendo a Martínez, el gesto de construcción identitaria y los avatares del etnocentrismo abren lugar para la articulación de procesos de etnificación y construcción discursiva colonial llevada a cabo con las otras subjetividades en estas tierras. En este contexto, son las prácticas culturales (y su performatividad) aquello que permite reflexionar 
acerca de nuevos horizontes de pregunta en los que "la semejanza y la diferencia" operan tensionados. Para ello tenemos que considerar que los cuestionamientos y sus grados de problematicidad no poseen un carácter definitivo, sino que una y otra vez van a ser puestos en movimiento desplegando una filología polilógica ${ }^{4}$ (Ette 2013) que, para nuestros intereses, entrega sentido a una reflexión filosófica política en ningún caso definitiva ni absoluta. Luego, y a la luz de un cuestionamiento por los espacios de producción y circulación de conocimientos en tiempos coloniales, remarcamos la idea de "espacios de movimiento" (Ette 2005, 2010) en cuanto nodos de encuentro-choque y vectorización, que pueden ser utilizados en la pregunta por la noción de indio.

Así también, es plausible integrar las propuestas filosóficas que consideramos consistentes y aplicables a una problematización relativo a la construcción de la noción de indio en América colonial. Nos referimos, especialmente, a los conceptos de "códigofagia" y "mestizaje cultural" (Echeverría 2001, 2005). Veamos esto:

El mestizaje cultural ha consistido en una "códigofagia" practicada por el código cultural de los dominadores sobre los restos del código cultural de los dominados. Ha sido un proceso en que el devorador ha debido muchas veces transformarse radicalmente para absorber de manera adecuada la substancia devorada; en el que la identidad de los vencedores ha tenido que jugarse su propia existencia intentando apropiarse de la de los vencidos (Echeverría 2001: 63).

La cita posiciona claramente ambas nociones en tanto que un ejercicio de devorar códigos culturales. Es ahí donde de forma codigofágica se construye un tipo de subjetividad limítrofe, fronteriza, en movimiento. Hablamos de una subjetividad que no encaja con el indio "en su sentido estricto" (etnocentrado), sino que apropia, agencia y redirecciona "en sentido amplio" los horizontes de comprensión identitarios y culturales de la conceptualización llamada: el indio. Esto último implica plantear nuevamente la pregunta por la identidad cultural. Frente a ello podemos seguir estas indicaciones:

Si la identidad cultural deja de ser concebida como una sustancia y es vista más bien como un "estado de código" -como una peculiar configuración transitoria de la subcodificación que vuelve usable, "hablable", dicho código-, entonces, esa "identidad" puede mostrarse también como una realidad evanescente, como una entidad histórica que, al mismo tiempo que determina los comportamientos de los sujetos que la usan o "hablan", está siendo hecha, transformada, modificada por ellos (Echeverría 2005: 31).

En consecuencia, la construcción de la noción de indio como "estado de código" compone una subjetividad "evanescente". El indio como identidad cultural (como código cultural) se forja en sus posibilidades para devorar y ser devorado. El abandono de una perspectiva sustancialista (en favor de una lectura semiótica) aleja a Echeverría del esencialismo culturalista latinoamericano. Luego, la "realidad evanescente" es parte de la transformación en donde lo indio está siendo constantemente reconstruido en tanto código cultural en la medida en que lo "usan y hablan".

Acerca de este punto es prudente reconocer que no son equivalentes todas aquellas subjetividades nombradas como indios, en consecuencia queremos distinguir un particular tipo de construcción discursiva dentro de lo indio, a saber, sus élites. Referencias pertinentes a las élites de indios son numerosas. No obstante, quisiéramos considerar particularmente aquellas relacionadas con la educación de los indios de élite en el contexto andino colonial. En estos estudios críticos denotamos certeras premisas hacia la construcción de textos culturales desde enfoques historiográficos, lingüísticos y antropológicos. Destacamos el análisis de los espacios y los modos de enseñanza-aprendizaje del español en términos de los conocimientos entre los cuales circulan los indios de élite (kurakas) en la zona andina colonial (Alaperrine-Bouyer 2002, 2005, 2007; Martínez 2011). Retomamos también las lectura en las que este tipo de subjetividades han sido identificadas como ladinas (Adorno 1989, 1992, 2007; Bernand 2001; Cornejo Polar 1994; Pratt 1991, 1997); o bien como passeurs (Estenssoro 2000; Gruzinski 2004, 2005; O'Phelan y Salazar 2005). Estas teorizaciones colaboran en la comprensión de los procesos de construcción de discursividades y subjetividades en las cuales los indios de élite procuran comunicar y posicionar sus pareceres escribiendo acerca de 
sí y de la historia de estas tierras. En rigor, estas teorizaciones nos permiten vectorizar las obras de nuestro corpus como traducciones culturales (Añón 2012), relevando sus adaptaciones y apropiaciones desde un enfoque atento a su condición de transferencia y circulación entre horizontes e imaginarios en contraste.

Ahora bien, nuestro objetivo es posicionar un acercamiento a las crónicas mestizas de Titu Cusi y Guamán Poma a modo de anclajes para la interpretación de la filosofía política presente en sus textos culturales. Para ello remarcamos que el contenido filosófico político responde -en términos generales-a un cuestionamiento por las formas de gobierno, la justicia y la libertad (Ferrater-Mora 2011). Un trabajo fundacional para el caso americano es el ya clásico ensayo de Zavala (1994), donde se cuestiona la lectura hecha respecto de los indios en la discusión hispana durante el siglo XVI en Salamanca (particularmente en el análisis de la disputa de Valladolid) y su impacto en la comprensión cristiana de la libertad como estadio preparatorio para la emancipación latinoamericana y sus corolarios republicanos. A diferencia de Zavala, el énfasis en nuestro acercamiento está puesto en las posibilidades de enunciación e interpretación que nuestros anclajes llevan a cabo por medio de textos culturales en los cuales se plasman intuiciones, ideas, nociones y argumentos posibles de comprender como evidencia de una reflexión filosófico política en articulación. En suma, buscamos un contenido filosófico político focalizado en la apropiación, la transferencia y la circulación de códigos de comprensión e interpretación del mundo de la vida. Por ello, la atención a la producción escrita de nuestros cronistas mestizos está relacionada con los corolarios que estas subjetividades consolidan al momento de pensar su lugar en los albores de la "modernidad occidental" (Echeverría 2005).

En consecuencia, es necesario remarcar un elemento fundamental en nuestro análisis relativo a la configuración de los textos culturales de los cronistas mestizos, a saber, la relación entre la escritura, la traducción y su agenciamiento y apropiación cultural en el área andina. Nos referimos a una reflexión encaminada a cuestionar los modos civilizatorios occidentales y, con ello, la fricción con la escritura como un modo civilizatorio hegemónico y como un horizonte de pregunta que involucra al indio y a su contenido filosófico político. Acerca de ello seguimos esta provocadora indicación:
Históricamente, personas que hablan quechua y aymara (como otros indígenas sudamericanos) han sido largamente descritos como eternos marginados del mundo de las letras. En efecto, algunos autores los han estereotipado como culturas "orales", y les han asignado un rol como trágicos resistentes rousseaunianos contra la regimentación alfabética. Pero esto está errado. Mientras más uno lee los menos conocidos archivos rurales, más uno se da cuenta que mucho de aquello que conocemos respecto de la cultura andina ha crecido en y mediante el alfabetismo. Si esto daña la apariencia de los andinos como una cultura "no occidental", mucho mejor. Esto nos lleva a un encuentro más realista con las personas de las altas planicies sudamericanas, en toda su distinción cultural, como actores dentro de la creación de la modernidad $^{5}$ (Salomon \& Niño-Murcia 2001: 1) [traducido por el autor].

La cita evidencia un axioma fundamental para comprender el fenómeno de la escritura y la traducción como un golpe a la "modernidad occidental" acontecido en los Andes sudamericanos. Destacamos el cuestionamiento atinente a la comprensión del mundo andino como un mundo "no occidental". Precisamente, debido a que la contraposición entre lo oral e iletrado y el sentido civilizatorio de la escritura contribuye al análisis crítico de los mecanismos y vehículos de enunciación en los cuales el indio ha encontrado su lugar en Occidente por medio de la creación de su modernidad. Ejemplos de este proceso creativo son los textos culturales de Titu Cusi y Guamán Poma, estos se posicionan "entre" perspectivas de análisis e interpretación precisamente porque presentan el traspaso de imaginarios y la consolidación de horizontes alternativos de pregunta y comprensión. Finalmente, ambos textos culturales señalan cercanías y lejanías con las indicaciones teórico-metodológicas anteriormente mencionadas. No obstante, referir al corpus seleccionado implica también dejarlo hablar, dejarlo mostrar aquellos especiales elementos, señas, indicaciones, marcas, que pueden redireccionar el sentido de la noción de indio. Dejar hablar al corpus implica, en este punto, rodear concéntricamente ambos textos culturales, sin progresión, destacando algunas "claves hermenéuticas" (Acevedo 2003) que interoperan en 
sus construcciones discursivas, y que persiguen, ulteriormente, una reflexión del indio tanto desde un contenido filosófico político como desde una identidad cultural en movimiento.

\section{Diego de Castro Titu Cusi Yupanqui y la "Instrucción" (1570)}

Es posible problematizar lo que hemos denominado como el contenido filosófico político de la noción colonial de indio por medio de una aproximación concéntrica atenta a los escritos producidos por algunos sujetos pertenecientes a las élites indias en el área andina. La célebre "Instrucción" (1570) puede ser considerada como uno de los primeros apuntalamientos ${ }^{6}$ del discurso de lo indio producidos por un indio, en este caso, uno importante, un inca. La posición de Titu Cusi es compleja dentro de un espacio de poder en plena reconfiguración política. Este contexto en disputa fortalece todo análisis en sus propuestas políticas. Sorprende el profundo contenido que este texto cultural despliega, no solo como relación histórica escrita por el vencido (Wachtel 1976), sino por la reconfiguración de elementos e instrumentos de análisis que direccionan sus meditaciones respecto de la destrucción de sus tradiciones y la pérdida de su poder político (Cattan 2011; Chang-Rodríguez 1988, 2005; Julien 2000, 2006; Regalado 1997). Para ello llevaremos a cabo un ejercicio crítico en el que distinguimos tres dimensiones de análisis e interpretación. La primera está relacionada con el rescate o regresión hacia la identidad del inca como argumento de autoridad. La segunda se refiere a los modos de agenciamiento y apropiación de la escritura junto con los procesos de traducción en los cuales Titu Cusi produce su texto cultural. La tercera contempla la lectura de las propuestas políticas que reposicionan el lugar del indio y cómo esta injerencia llega a ser parte de la vectorización del imaginario colonial andino, esbozando un contenido filosófico político.

Respecto de la primera dimensión no podemos omitir el profundo impacto del inca como figura arquetípica del hombre andino colonial (Pease 2012). La autoridad del inca es un punto determinante en la construcción de la noción de indio en los Andes coloniales, precisamente porque se articula a partir de una autoridad en decadencia. Lo incaico en Titu Cusi viene por su sangre. Su historia de vida es interesante y en muchos casos demuestra la complejidad de sus propuestas (Cattan 2011; Julien 2006). La nobleza del inca no es gratuita; Titu Cusi la instrumentaliza como parte de un ejercicio crítico y formativo de una identidad en movimiento. Reconocemos en la configuración identitaria de Titu Cusi sobre el inca una forma que necesita explicar su contenido. Para ello, ubica a Manco Inca como el enlace para afirmar su legitimidad y nobleza:

Eres mi primero hijo y heredero de mi reino y esta es mi postrimera voluntad. Yo confío de su bondad de todos ellos que te acataran y respetaran por tal, y que no harán más de lo que yo les he mandado y tú les dijeres (Yupanqui 1992: 61-62 [1570]).

Aquí es clara la operatividad de patrones comparativos relativos a los códigos culturales europeos de sucesión y herencia ("primero hijo y heredero de mi reino"). Sin embargo, el asunto de la autoridad del inca es posicionado por varios personajes arquetípicos (Atahualpa, Vila Oma y Manco Inca, entre otros). En ellos se relevan y distinguen modos, espacios y sujetos de poder. Titu Cusi sabe que su autoridad como inca no es comparable con la autoridad previa ejercida por el inca durante el Tawantinsuyu. En este sentido, Titu Cusi agencia y apropia códigos culturales hispanos (europeos) a fin de reclamar la autoridad acerca de lo incaico mediante un texto escrito. Esto significa que aquellos agenciamientos y apropiaciones de tecnologías y estructuras de sentido occidentales tienen profundidad y continuidad en la construcción andina de autoridad y poder. Bien sabemos que en la "Instrucción" el enlace entre autoridad, poder e identidad es siempre difícil. No podemos alejarnos de los movimientos y adaptaciones que hubo en el contexto de producción del texto cultural de Titu $\mathrm{Cusi}^{7}$. Ahora bien, aludiendo al objetivo de su "Instrucción" sostiene Titu Cusi:

En esta quiero declarar el cómo yo me he habido después de sus días [de Manco Inca] y la manera por dónde me he venido a tornar cristiano y tener paz con los españoles, que fue mediante Dios (Yupanqui 1992: 62 [1570]).

Estas líneas canalizan asuntos centrales para su estrategia de persuasión. Destacamos el fundamento 
vivencial, la experiencia de vida ("cómo yo me he habido"). Este es un recurso retórico que identificamos claramente con el género literario de la crónica (Stoll 1998). La estrategia de persuasión se funda en el autorreconocimiento de su cristiandad ("la manera por dónde me he venido a tornar cristiano") junto a una clara señal de capitulación y no beligerancia ("tener paz con"). Todo ello validado por un argumento ontológico (teológico) irrefutable ("que fue mediante Dios"). Finalmente, en las palabras de Titu Cusi es posible reconocer un recurso comparativo (y creativo) que funciona de modo estratégico, persuasivo, incluso reflexivo, y que está determinado por la reconfiguración identitaria del inca y su autoridad durante el exilio en Vilcabamba. Esta reconfiguración está ulteriormente focalizada en relevar la noción de indio como inca, como cristiano y como noble (Cattan 2011).

La segunda dimensión procura reconocer los espacios y movimientos de agenciamiento y apropiación, de transferencia y circulación, particularmente en la escritura y la traducción llevada a cabo por Titu Cusi. En este nivel hay algunas indicaciones que tienen directa relación con el modo en el que se va construyendo la "Instrucción" como texto y traducción cultural. Podemos cuestionar quién, cómo y por qué ${ }^{8}$ se desarrolla esta narración histórico literaria (Cattan 2011) que logra interrelacionar estrategias discursivas y tecnologías de comunicación occidentales en favor de un proyecto de reconstrucción cultural e identitaria. En este contexto podemos seguir a Titu Cusi, particularmente en su comprensión en torno a la relación entre la letra y la memoria:

Y porque la memoria de los hombres es débil y flaca y si no nos acurrimos [sic] a las letras para nos aprovechar de ellas en nuestras necesidades era cosa imposible podernos acordar por extenso de todos los negocios largos y de importancia (Yupanqui 1992: 3 [1570]).

Es evidente el conocimiento del valor político y mnemotécnico de las letras. Su obra nos posiciona en la pregunta por el sentido de la escritura en la zona andina. En los Andes el sentido de la escritura y la construcción discursiva como proceso sociocultural no dirige solamente a capturar el discurso con la letra, sino que a transformarlo por medio de un lenguaje del recuerdo (Abercrombie 1991, 1998;
Salomon 1984, 1994, 1999). Entonces, la escritura y la traducción como vehículos para la transformación del discurso conducen al recuerdo, la rememoración y al reconocimiento de una creación o recreación -siguiendo nuestra propuesta-referida a la noción de indio. Con ello, el sentido de la "Instrucción" como texto y traducción cultural está relacionado con una producción escritural que busca reconstruir la memoria andina e incaica en la medida en que la transforma por un ejercicio narrativo históricoliterario. En este punto, es necesario destacar el concepto de "escritura andina polifónica" o bien "escritura coral" (Mazzotti 1996). Podemos incorporar este concepto al análisis concerniente a la "Instrucción" como un ejemplo temprano para un modo alternativo de construcción literaria. Este modo de escritura se constituye desde la diferencia e interacción entre el "sujeto de escritura" y el "sujeto de lectura" (Mazzotti 1996: 17-18). En Titu Cusi, en su redacción compartida y traducida, se muestra no solo una "relación de servicios" (Mazzotti 1996: 86), sino también como un modelo inicial para una construcción discursiva que vectoriza "múltiples voces" y que se compone desde las constantes "interferencias entre el quechua y el español", entre lo oral y lo escrito, configurando una narración histórico literaria de forma "polifónica" o "coral" (Mazzotti 1996: 98-99).

Respecto de la tercera dimensión de análisis es posible integrar el alcance del problema fundamental llamado: modernidad occidental. Desde ahí es posible desplegar un cuestionamiento relacionado con la contraposición de proyectos civilizatorios, es decir, en la contraposición entre Occidente (y su creación -expansión-) con lo "otro", con los otros mundos en los cuales subjetividades tales como Titu Cusi deben redefinir su lugar. Este encuentrochoque establece un cuestionamiento acerca de los horizontes simbólicos y los imaginarios que Occidente construye según su propia trayectoria civilizatoria (Echeverría 2005, 2010). Cuando se entiende que la conquista es un proceso histórico cultural aún en construcción, se entiende también que el proyecto civilizatorio de Titu Cusi estaba en decadencia, particularmente por su carácter utópico (Echeverría 2011). El proyecto civilizatorio de la modernidad occidental condena y purga todo proyecto alternativo, lo devora en su propio horizonte, mas no por ello lo clausura. Precisamente, debido al grado de "mestizaje cultural" (Echeverría 2005: 19-31) en términos de la recreación identitaria de lo indio. 
Aquí el contenido filosófico político está en directa relación o bien negociación con Occidente. A partir de modos de enunciación complejos, a saber, recursos y figuras literarias, retóricas, poéticas, se funda una narrativa alternativa e imposible de los hechos de la Conquista que rompe (y se legitima) con la tradición occidental (Salomon 1984, 1994, 1999). El "ocaso del inca" (Echeverría 2011) o bien su decadencia, narrada en los personajes arquetípicos y su derroteros, se articula en términos positivos, pues nos permite interpretar y vectorizar los modos de adecuación y de reconstitución identitaria. Finalmente, el contenido filosófico político se resume en el reconocimiento y la validez de un tipo de indio que reclama y demanda su lugar (un no lugar) en los albores de la modernidad occidental. Titu Cusi articula un ethos -que comprendemos en tanto que un comportamiento o costumbre, un modo de vida que se bifurca de la modernidad occidental como "barroco" (Echeverría 2005: 161-224)- que opera como una estrategia de persuasión basada en la apropiación activa de códigos culturales (códigofagia). En suma, el texto cultural de Titu Cusi se constituye por su narrativa histórico literaria como parte de una construcción cultural e identitaria, que evidencia y produce espacios y vehículos para la reconstrucción de una reflexión político filosófica sobre y desde el indio en los Andes coloniales.

\section{Felipe Guamán Poma de Ayala y "El Primer Nueva Corónica y Buen Gobierno" (1615)}

La importancia de Felipe Guamán Poma de Ayala para los estudios andinos es central. Esta obra ha funcionado como plataforma versátil al momento de volver la mirada hacia el mundo andino colonial. Rastrear las referencias bibliográficas permite identificar los diferentes modos de comprensión e interpretación que han cruzado "El Primer Nueva Corónica y Buen Gobierno" (Curatola 2003). Los trabajos de Adorno (1989), Chang-Rodríguez (1988, 2005), López-Baralt (1988), Murra (1968, 1980, 2002), Ossio (1973, 2008), Pease (1995), Porras Barrenechea (1948), entre muchos otros, son canónicos. Buscamos dimensionar y enlazar la construcción de un imaginario tensionado y relacionado con un ejercicio enunciativo que posiciona una crítica al orden colonial hispano (Adorno 1989; Quispe-Agnoli 2006) mediante la afirmación de propuestas políticas tendientes a desmontar y enmendar el "crisol cultural" (Bernand y Gruzinski 1999) de los Andes coloniales. Pues bien, como discurrimos acerca del texto cultural de Titu Cusi, queremos destacar tres dimensiones o niveles de análisis e interpretación presentes en la obra de Guamán Poma. La primera está relacionada con el rescate o regresión hacia la identidad del inca como un argumento de autoridad y validación política. La segunda refiere a los modos de agenciamiento y apropiación de la escritura junto con los procesos de traducción en los que Guamán Poma produce su texto cultural. La tercera contempla las propuestas políticas que reposicionan el lugar del indio en el imaginario colonial andino, construyendo un contenido filosófico político.

Respecto de la primera dimensión queremos distinguir las indicaciones de Guamán Poma a la historia del incario como parte de un entramado mayor: la historia andina (Murra 1980; Ossio 2008; Pease 1995). Luego de la descripción de las "edades de los indios" (Guamán Poma 1980: 41-61 [1615]) se ubica la entrada del inca en la "Nueva Corónica". En esta parte del texto se desarrolla la explicación guamampina relativo a lo incaico desde diversos puntos de vista, produciendo diferentes descripciones "autoetnográficas" (Pratt 1991, 1997), como las genealogías de incas, collas y capitanes (Guamán Poma 1980: 63-167 [1615]), diversas indicaciones acerca del calendario, los ritos y las festividades religiosas, de la administración política incaica, cada una con particulares detalles (Guamán Poma 1980: 275-337 [1615]). He ahí el exhaustivo ejercicio de traducción cultural realizado por Guamán Poma en cada una de sus descripciones y correspondientes dibujos. Dentro de los diversos modos de exposición acerca de lo incaico reconocemos un discurso problemático y "ambiguo" (Husson 2001). Hablamos de una relación particular (ambigua) con el mundo incaico al momento de proponer un sistema de gobierno para los indios andinos. En su texto Guamán Poma establece diferentes propuestas y enmiendas de carácter político, salvaguardando y explicando elementos del modelo incaico como un modelo de virtud moral dentro de su gentilidad. Al parecer la estrategia es retrotraer la virtud endógena del "Buen Gobierno" de los indios -y de los incas- (Guamán Poma 1980: 405-454 [1615]) en abierta contraposición a la veleidosa administración exógena llevada a cabo por los españoles por medio de sus autoridades e instituciones imperiales y religiosas, principalmente de corregidores, padres y 
visitadores (Guamán Poma 1980: 455-652 [1615]). Ciertamente, el recurso incaico se legitima como modelo de virtud en la administración política del área andina (Murra 2002; Husson 2001). No obstante, el lugar del inca en la "Nueva Corónica" no se reduce a su virtud moral, política o administrativa. Atendemos a la noción del inca en su texto cultural como un argumento ad hominem que vectoriza al inca como indio en un "sentido amplio" porque retoma selectivamente componentes simbólicos de autoridad y poder incaicos (andinos) incluyéndolos "de contrabando" (Salomon 1984) dentro de un imaginario hispano (occidental) en construcción. Ergo, es preciso reconocer en la "Nueva Corónica" un discurso de reinscripción que integra lo incaico en la medida en que lo explica. Reconocemos esto como una estrategia persuasiva que permite explicar y diferenciar la experiencia histórica andina, en donde el inca es establecido como un elemento simbólico y constitutivo de lo andino porque contiene autoridad y reconocimiento político cultural.

La segunda dimensión se refiere a los modos de agenciamiento y apropiación de la escritura y la traducción. Para ello es posible seguir la conceptualización de Guamán Poma como indio ladino (Adorno 1988, 1991, 2007; Bernand 1998, 2001; Pratt 1991; Quispe-Agnoli 2005, 2006). Lo ladino o bien la ladinidad de Guamán Poma destaca como un enlace entre mecanismos y vehículos de construcción discursiva en un ejercicio de traducción cultural. No son los 400 dibujos y sus extraordinarios detalles aquello que demuestra la capacidad de sortear vehículos y modulaciones para el intercambio de códigos culturales en el mundo andino colonial (López-Baralt 1988). En este punto podemos llevar a cabo un acercamiento teórico relacionado con la noción de "subalternidad" (Spivak 1987, 1999) mediante el concepto de "sabotaje afirmativo" ${ }^{10 " ~(S p i v a k ~ 2012) . ~ E s t e ~}$ concepto remarca la interoperación entre tecnologías de conocimiento y comunicación occidentales (europeas) y aquellas no occidentales, en nuestro caso, andinas. El sabotaje afirmativo expone un doble vínculo (Spivak 2012) como un movimiento obstaculizador a la vez que regenerativo atingente a una subjetividad subalterna y sus procesos de enunciación y construcción discursiva. Guamán Poma sabotea afirmativamente desde su ladinidad porque despliega un doble vínculo (obstáculo y creación), un posicionamiento reflexivo que utiliza diferentes instrumentos, tecnologías, modelos, imaginarios y horizontes de sentido occidentales y no occidentales en la composición de una narrativa histórico literaria. Finalmente, es el agenciamiento de la escritura y la traducción en la obra de Guamán Poma aquello que opera dentro de un complejo sistema de intercambio (de códigos culturales), y construye una subjetividad subalterna dispuesta a redireccionar sus posibilidades de enunciación como indio en los Andes coloniales.

Respecto de la tercera dimensión podemos relevar algunos elementos particularmente funcionales en la composición del contenido filosófico político respecto de la noción de indio. La segunda parte de la "Nueva Corónica" refiere explícitamente a la condición del indio andino y sus posibilidades de determinación política. Guamán Poma demuestra cómo la noción de indio era insuficientemente comprendida en el imaginario colonial hispano. Sabemos que el indio como construcción discursiva está siempre ligado a la condición secundaria, en oposición a otras, construida desde y contra otras (españoles, europeos, mestizos, negros, ladinos, salvajes, extranjeros). Por ello Guamán Poma insiste en establecer variadas precisiones explicativas que son descritas bajo la necesidad de satisfacer la complejidad conceptual del indio. A lo largo de su obra despliega diferentes niveles de comparación, análisis e interpretación de carácter genealógico, de parentesco, político, histórico, religioso, teológico, referidos a asuntos sociales, morales, económicos, urbanos y geográficos, por nombrar algunos, en ellos su caracterización acerca de la noción de indio va tomando forma. El contenido filosófico político fundamental en el texto de Guamán Poma integra una identidad doble: indio y cristiano. Guamán Poma procura argumentar la categoría de indio bajo esta doble agencia de forma estratégica, particularmente porque es el indio quien debe conducir y salvaguardar el "Buen Gobierno" en el orden colonial.

Podemos relacionar esta lectura con la modernidad occidental y sus modos de expansión en el área andina colonial. Bien sabemos que el contenido filosófico político de la noción de indio en Guamán Poma está rodeado por la modernidad occidental. Es ahí donde el efecto de su "sabotaje afirmativo" (Spivak 2012) posiciona una propuesta política por medio del indio como identidad reconstruida a la vez que occidentalizada. Esta es sin duda una respuesta elaborada, una propuesta política que reinventa un lugar de poder para el indio andino sin dejar de lado su historicidad ni tampoco su cercanía/lejanía 
con el proyecto civilizatorio europeo. Finalmente, la pregunta por el contenido filosófico político del indio en la "Nueva Corónica" nos conduce a la recomposición de sus posibilidades de enunciación y construcción discursiva. En rigor, el objetivo de Guamán Poma no es otro que vectorizar la identidad del indio andino en el imaginario occidental otorgándole un nuevo lugar en el orden colonial hispano. Entonces, el proyecto guamampino sostiene una posición subalterna, saboteadora, consciente, y sostiene también un continuo rescate y rememoración de elementos culturales propios (andinos) que se despliegan en un ejercicio crítico de apropiación y agencia de los modelos occidentales (hispanos, europeos). El indio andino contiene un sentido filosófico político que no supera sino que compara y devora los horizontes de comprensión y de pregunta que se ubican dentro/fuera, en los límites, de la modernidad occidental.

\section{Consideraciones finales}

Hemos bosquejado la reflexión filosófico política presente en las crónicas mestizas de Titu Cusi y Guamán Poma. Para ello ha sido necesario romper con algunos prejuicios acerca del carácter filosófico de este tipo de textos culturales. Proponemos volver a estas obras como nuevos espacios y registros en forma de desenlaces discursivos posibles de explorar y explotar filosóficamente. Respecto de ello, remarcamos esta avizora indicación:

¿Cuáles son los lugares, emplazamientos y desenlaces discursivos a los que debemos acudir para encontrar esa filosofía dispersa, ya que no podemos hacerlo en la tradición de nuestras universidades ni en nuestras escuelas de filosofía? No se trata, por supuesto, de buscar filosofía en todos y cada uno de los registros habituales de la literatura, la historiografía, el pensamiento jurídico-político, la antropología o materias afines, sino de encontrar y examinar crítica y reflexivamente fragmentos de discurso (o sistemas de dispersión) cuyos registros, justamente por su indudable perfil y hondura filosófica, se reconocen incidental y transitoriamente entretejidos en textos literarios, historiográficos, jurídicos-políticos, antropológicos y aun técnico-científicos particulares (Ortega 2011: 40).
Seguimos a Ortega en su pregunta por los "lugares" y los "emplazamientos" para una filosofía nómada, móvil y "dispersa". Coincidimos en su indicación atinente a la imbricación (entretejido) presente en niveles alternativos de registro ("sistemas de dispersión" fragmentarios) que contienen una calidad filosófica "por su indudable perfil y hondura". Seguimos la propuesta hacia nuevos materiales y recursos donde rastrear un pensamiento filosófico. Nosotros hemos emplazado dos casos particulares, en ellos identificamos su profundidad reflexiva.

Sabemos que Titu Cusi y Guamán Poma intentaron reinventar un modo de pensamiento filosófico, que podemos llamar "andino" (Estermann 1998; Kusch 1999; Martínez 2002), dentro del que buscamos su modulación filosófico política. Esto que nombramos abiertamente como pensamiento filosófico andino se forma en tensión con el pensamiento filosófico europeo, principalmente debido al uso de la letra como vehículo o arma para su enunciación. Esto determina un tipo de reflexión que se da por medio de la escritura y sus modos de operatividad (traducción cultural) en cuanto que mecanismos para la construcción discursiva de subjetividades indias. Esto, además, nos lleva a advertir los altos grados de complejidad (transferencia y circulación de conocimientos) en los cuales se forjaron ambos textos culturales. Este asunto es fundamental, pues permite entender por qué las crónicas mestizas son espacios para un pensamiento filosófico toda vez que son nodos para la interconexión entre horizontes e imaginarios en movimiento y que provocan la reinvención de una identidad cultural en la noción de indio y su contenido filosófico político. Nuestro objetivo ha sido realizar una aproximación a este asunto contemplando la profundidad de esta reflexión en Titu Cusi y Guamán Poma. Sus obras reclaman y posicionan derechos, señalan deberes, de distinta manera, por diferentes vías, retrotrayendo y funcionalizando elementos histórico culturales. Dentro de esto, hemos destacado que el "momento" del inca condensa un modelo de comprensión para la noción del indio (y de lo andino). Hemos señalado que tanto Titu Cusi como Guamán Poma introducen "de contrabando" (Salomon 1984) normas y elementos de legitimidad incaica. Luego, el inca se despliega como ejemplo de nobleza, virtud moral y policía, una vez que se explica su gentilidad y se acepta su cristiandad. 
Ahora bien, la noción de indio pensada en movimiento no contempla solamente lo incaico dentro de su reconfiguración cultural. Hemos tratado la cuestión de la modernidad occidental y su proyecto civilizatorio en tanto un proceso de colisión e imposición que -en el caso americano- se bifurca hacia un "horizonte de comprensión alternativo" (Echeverría 2011). Cualquier análisis acerca del contenido filosófico político en la noción de indio acarrea una tensión de "larga duración" (Braudel 2013) con el proyecto civilizatorio de la modernidad occidental. Siguiendo esta idea, la trayectoria de la modernidad occidental se expande hacia los Andes coloniales y produce construcciones discursivas alternativas, como el indio. Este asunto es complicado porque introduce bifurcaciones en el proyecto civilizatorio de la modernidad occidental, precisamente debido al surgimiento de múltiples construcciones discursivas y subjetividades alternativas que se configuran "dentro" del proyecto civilizatorio occidental. Hemos sostenido que en los Andes coloniales estas subjetividades otras despliegan mecanismos de enunciación para textualizar y rememorar "lo imposible" (Salomon 1984, 1994, 1999). Los escritos de Titu Cusi y Guamán Poma ejecutan un posicionamiento determinante debido a "la concreción histórica de la cultura" (Echeverría 2005: 136-139) que se despliega mediante sus palabras. En el detalle de su producción histórico literaria se vectorizan las huellas de otra modernidad, distinta pero equivalente, que no ha cesado en su desarrollo pese a la tormenta en la que se ha visto inserta desde su creación. Esta otra modernidad no es posmoderna porque el indio no se conduce por medio de grandes ideales civilizatorios. Esta otra modernidad se articula entre la apropiación y el intercambio, en un movimiento de resistencia y reexistencia, que opera saboteando afirmativamente y que rememora sus propias trayectorias en un ejercicio de supervivencia y recreación reflexiva respecto de su identidad cultural mediante una narración con carácter filosófico.

Nuestras aproximaciones se han focalizado en algunas útiles perspectivas relativas a la construcción discursiva llamada el indio en las crónicas mestizas de Titu Cusi y Guamán Poma. Es ahí donde ambas crónicas mestizas -en cuanto "sistemas de dispersión discursiva" (Ortega 2011)- nos permiten rastrear las huellas de un sendero aún en descubrimiento. Hablamos de una reflexión en movimiento, de un gesto nómade, tendiente a comprender el lugar del indio en los albores de la modernidad occidental por medio de la interacción entre modulaciones y construcciones identitarias (códigos culturales) que se permean y se yuxtaponen, que se abren y vectorizan, "en" la noción de indio. Es ahí donde cualquier aproximación teórica acerca de este tipo de textos culturales, en sus mecanismos de enunciación y reflexión filosófico política, no se cierra a la posibilidad de perseguir y persistir en el cuestionamiento pertinente a un problema central, siempre en construcción, a saber, la noción de indio en los Andes coloniales.

\section{Referencias Citadas}

Abercrombie, $\mathrm{T}$.

1991 Doble Articulación y Etnogénesis. En Reproducción y Transformación de las Sociedades Andinas. Siglos XVI$X X$, compilado por Segundo Moreno y Frank Salomon, pp. 197-212. Abya-Yala, Quito.

Abercrombie, $\mathrm{T}$.

1998 Pathways of Memory and Power. University of Wisconsin Press, Madison.

Acevedo, J.

2003 En torno a la Interpretación Heideggeriana del Principio de Razón Suficiente. Revista Diálogo 81: 15-34.

Adorno, R.

1989 Cronista y Príncipe. La obra de Don Felipe Guamán Poma de Ayala. Pontificia Universidad Católica del Perú, Lima.

Adorno, R.

1992 El Indio Ladino en el Perú Colonial. En De palabra y obra en el Nuevo Mundo. Imágenes Interétnicas, editado por Miguel León-Portilla, Edna Acosta Belén y José Jorge Klor de Alva, pp. 369-395. Siglo Veintiuno, México.
Adorno, R.

2007 The Polemics of Possession in Spanish American Narrative. Yale University Press, New Haven.

Alaperrine-Bouyer, $\mathrm{M}$

2002 Saber y Poder: la Cuestión de la Educación de las Élites Indígenas. Incas e Indios Cristianos. En Élites Indígenas e Identidades Cristianas en los Andes Coloniales, editado por Jean-Jacques Decoster, pp. 145-167. Centro Bartolomé de las Casas - Instituto Francés de Estudios Andinos-Asociación Kuraka, Cuzco.

Alaperrine-Bouyer, $\mathrm{M}$.

2005 La Biblioteca del Colegio de Yngas Nobles: San Borja del Cuzco. Revista Histórica 29: 163-179.

Alaperrine-Bouyer, $\mathrm{M}$.

2007 La Educación de las Elites Indígenas en el Perú Colonial. Instituto Francés de Estudios Andinos - Instituto Riva Agüero, Lima.

Añón, $\mathrm{V}$.

2012. La Palabra Despierta. Tramas de la Identidad y Usos del Pasado en las Crónicas de la Conquista de México. El Corregidor, Buenos Aires. 
Bachmann-Medick, D.

2006 Cultural Turns. Neuorientierung in den Kulturwissenschaften. Rowohlt Taschenbuch, Berlin.

Bernand, C.

1998 El Mundo Andino: Unidad y Particularismo. En Descubrimiento, Conquista y Colonización de América a Quinientos años, compilado por Carmen Bernand, pp. 108111. Fondo de Cultura Económica, México.

Bernand, C.

2001 Mestizos, Mulatos y Ladinos en Hispanoamérica: un Enfoque Antropológico de un Proceso Histórico. En Motivos de la Antropología Americanista. Indagaciones en la Diferencia, coordinado por Miguel León Portilla, pp. 105-131. Fondo de Cultura Económica, México.

Bernand, C. y Gruzinski, S.

1996 Historia del Nuevo Mundo. Tomo I. Del Descubrimiento a la Conquista. La Experiencia Europea, 1492-1550. Fondo de Cultura Económica, México.

Bernand, C. y Gruzinski, S.

1999 Historia del Nuevo Mundo. Tomo II. Los Mestizajes (1550-1640). Fondo de Cultura Económica, México.

Braudel, F.

2013 El Mediterráneo y el Mundo Mediterráneo en la Época de Felipe II. Fondo de Cultura Económica, México.

Cattan, M.

2011 En los Umbrales de la Instrucción de Titu Cusi Yupanqui. Revista Histórica. 35: 7-44.

Chang-Rodríguez, R.

1988 La Apropiación del Signo. Tres Cronistas Indígenas del Perú. Arizona State University, Tempe.

Chang-Rodríguez, R.

2005 La Palabra y la Pluma en Primer Nueva Corónica y Buen Gobierno. Pontificia Universidad Católica del Perú, Lima.

Cornejo Polar, A.

1994 Escribir en el Aire. Ensayo sobre la Heterogeneidad sociocultural en las Literaturas Andinas. Horizonte, Lima.

Curatola, M.

2003 El Códice Ilustrado (1615/1616) de Felipe Guamán Poma de Ayala: Hacia una Nueva era de Lectura. Colonial Latin American Review 12: 251-258.

Echeverría, B.

2001. Las Ilusiones de la Modernidad. Tramasocial, Quito.

Echeverría, B. 2005 La Modernidad de lo Barroco. Era, México.

Echeverría, B. 2010. Modernidad y Blanquitud. Era, México.

Echeverría, B.

2011 El Ocaso del Inca. En Antología Bolívar Echeverría. Crítica de la modernidad capitalista, editado por Gonzalo Gonsalvez, pp. 203-208. Vicepresidencia del Estado Plurinacional de Bolivia - OXFAM, La Paz.

Estenssoro, J.

2000 Los Colores de la Plebe: Razón y Mestizaje en el Perú Colonial. En Los Cuadros de Mestizaje del Virrey Amat. La Representación Etnográfica en el Perú Colonial, editado por Natalia Majluf, pp. 67-107. Museo de Arte de Lima, Lima. Estermann, J. 1998 Filosofía Andina. Abya-Yala, Quito.

Ette, $\mathrm{O}$.

2005 ZwischenWeltenSchreiben: Literaturen ohne festen Wohnsitz. Kadmos, Berlin.
Ette, O.

2010 Con Palabras del Otro. Un Excelente Traductor es un Magnífico Mentiroso. Revista Humboldt 153: 16-19.

Ette, O.

2013 Viellogische Philologie. Die Literaturen der Welt und das Beispiel einer Transarealen Peruanischen Literatur. Kadmos, Berlin

Guamán Poma de Ayala, F.

1980 [1615] El Primer Nueva Corónica y Buen Gobierno. Siglo Veintiuno, México.

Gruzinski, S.

2004 La Colonización de lo Imaginario. Sociedades Indígenas y Occidentalización en el México Español. Siglos XVI-XVIII. Fondo de Cultura Económica, México.

Gruzinski, S.

2005 Introducción. En Passeurs, Mediadores Culturales y Agentes de la Primera Globalización en el Mundo Ibérico, siglos XVI-XIX, editado por Scarlett O'Phelan y Carmen Salazar, pp. 13-33. Instituto Francés de Estudios Andinos, Lima.

Heidegger, $\mathrm{M}$.

2003 Sery Tiempo. Buenos Aires, Fondo de Cultura Económica.

Husserl, E.

2005 Erfahrung und Urteil. Prag, Academia.

Husson, J.

2001 La Idea de Nación en la Crónica de Felipe Guamán Poma de Ayala: Sugerencias para una Interpretación Global de El Primer Nueva Corónica y Buen Gobierno. Revista Histórica 25: 99-134.

Julien, C.

2000 Reading Inca History. University of Iowa Press, Iowa. Julien, C

2006 Introduction. En History of How the Spaniards Arrived in Peru, por Titu Cusi Yupanqui, pp. VII-XXXV. Hackett Publishing, Cambridge.

Kuhn, $\mathrm{H}$.

1940 The Phenomenological Concept of Horizon. En Philosophical Essays in Memory of Edmund Husserl, editado por Marvin Faber. pp. 106-123. Cambridge, Harvard University Press.

Kusch, R.

1978 América Profunda. Biblios, Buenos Aires.

Lienhard, M.

1983 La Crónica Mestiza en México y el Perú hasta 1620: Apuntes para su Estudio Histórico-Literario. Revista de Crítica Literaria Latinoamericana 17: 105-115.

López-Baralt, M.

1988 La Crónica de Indias como Texto Cultural: la Articulación de los Códigos Icónico y Lingüístico en los Dibujos de la Nueva Corónica de Guamán Poma. Revista Iberoamericana 120-122: 461-531.

Martínez, J.

2002 La Construcción de Identidades y de lo Identitario en los Estudios Andinos. Ideas para un Debate. En Identidades y Sujetos. Para una Discusión Latinoamericana, editado por José Luis Martínez, pp. 89-112. Facultad de Filosofía y Humanidades Universidad de Chile, Santiago.

Martínez, J.

2007 Construyendo Mundos: el Nacimiento de los Indios en los Andes del siglo XVI. En Del Nuevo al Viejo Mundo: Mentalidades y Representaciones desde América, editado por 
Alejandra Araya, Azún Candina y Celia Cussen, pp. 23-34. Fondo de Publicaciones Americanistas, Santiago.

Martínez, P.

2011 Algunas Reflexiones sobre las Prácticas Escriturarias en los Andes Coloniales (siglo XVII). Revista Atenea 503: 93-109.

Mazzotti, J.A.

1996 Coros Mestizos del Inca Garcilaso. Resonancias Andinas. Fondo de Cultura Económica, Lima.

Murra, J.

1968 Guamán Poma de Ayala: A Seventeenth-Century Indian's Account of Andean Civilization. Natural History 70: 35-63.

Murra, J.

1980 Waman Puma, Etnógrafo del Mundo Andino. En El Primer Nueva Corónica y Buen Gobierno, Felipe Guamán Poma de Ayala, pp. XIII-XIX. Siglo Veintiuno, México.

Murra, J.

2002 El Mundo Andino: Población, Medio Ambiente y Economía. Pontificia Universidad Católica del Perú e Instituto de Estudios Peruanos (Historia Andina 24), Lima.

O'Gorman, E.

2004 La Invención de América. Fondo de Cultura Económica, México.

O'Phelan, S y Salazar, C. (Eds)

2005 Passeurs, Mediadores Culturales y Agentes de la Primera Globalización en el Mundo Ibérico, siglos XVI$X I X$. Instituto Francés de Estudios Andinos, Lima.

Ortega, A.

2011 ¿Qué Pregunta la Filosofía desde América? En Filosofía desde América. Temas, Balances y Perspectivas, coordinado por Ana Cristina Ramírez, pp. 17-44. Abya-Yala, Quito.

Ossio, J.

1973 Ideología Mesiánica del Mundo Andino. Ediciones Ignacio Pastor, Lima.

Ossio, J.

2008 En Busca del Orden Perdido. La Idea de la Historia de Felipe Guamán Poma de Ayala. Pontificia Universidad Católica del Perú, Lima.

Pagden, A.

1988 La Caída del Hombre Natural. Alianza, Madrid.

Pease, F.

1995 Las Crónicas y los Andes. Fondo de Cultura Económica, Lima.

Pease, F.

2012 Los Incas en la Colonia. Estudios sobre los siglos XVI, XVII y XVII en los Andes. Ministerio de Cultura, Lima.

Pérez Cantó, $M$.

1996 El Buen Gobierno de don Felipe Guamán Poma de Ayala. Abya-Yala, Quito.

Porras Barrenechea, R.

1986 Los Cronistas del Perú: 1528-1650 y Otros Ensayos. Banco del Crédito del Perú, Lima.

Pratt, M.

1991 Arts of the Contact Zone. Profession 91: 33-40.

Pratt, M.

1997 Ojos Imperiales. Universidad Nacional de Quilmes, Buenos Aires.

Quispe-Agnoli, R.

2005 Cuando Occidente y los Andes se Encuentran: Qellqay, Escritura Alfabética, y Tokhapu en el siglo XVI. Colonial Latin American Review 14: 263-298.

Quispe-Agnoli, R.

2006 Lafe Andina en la Escritura: Resistencia e Identidad en la obra de Guamán Poma de Ayala. Universidad Nacional Mayor de San Marcos, Lima.
Rama, A.

2004 La Ciudad Letrada. Tajamar Editores, Santiago.

Regalado, L.

1997 El Inca Titu Cusi Yupanqui y su Tiempo. Universidad Católica del Perú, Lima.

Salomon, F.

1984 Crónica de lo Imposible: Notas sobre tres Historiadores Indígenas Peruanos. Chungara. Revista de Antropología Chilena 12: 81-98.

Salomon, F.

1994 La Textualización de la Memoria en la América Andina: Una Perspectiva Etnográfica Comparada. América Indígena 54: $229-261$

Salomon, F.

1999 Testimonies: The Making and Reading of Native South American Historical Sources. En The Cambridge History of the Native Peoples of the Americas, Vol. 3. Part 1. South America, editado por Stuart Schwarz y Frank Salomon, pp. 19-95. Cambridge University Press, Cambridge.

Salomon, F.

2003 Testimonios en Triángulo: Personajes de la Nueva Corónica de Guamán Poma y del Manuscrito Quechua de Huarochirí en el Pleito sobre el Cacicazgo Principal de Mama (1588-1590). Chungará. Revista de Antropología Chilena 35: 253-268.

Salomon, F. y Niño-Murcia, M.

2001 The Lettered Mountain: A Peruvian Village's Way with Writing. Duke University Press, Durham

Spivak, G.

1987 In Other Worlds: Essays in Cultural Politics. Methuen, London.

Spivak, G.

1999 A Critique of Postcolonial Reason: Towards a History of the Vanishing Present. Harvard University Press, Cambridge.

Spivak, G.

2012 An Aesthetic Education in the Era of Globalization. Harvard University Press, Cambridge.

Stoll, E.

1998 Géneros en la Historiografía Indiana: Modelos y Transformaciones. En Competencia Escrita, Tradiciones Discursivas y Variedades Lingüísticas: Aspectos del Español Europeo y Americano en los Siglos XVI y XVII: Coloquio Internacional, Friburgo en Brisgovia, 26 - 28 de Septiembre de 1996, editado por Wulf Oesterreicher, Eva Stoll y Andreas Wesch, pp. 143-168. Gunter Narr, Tübingen.

Stoll, E.

2010 Competencia Escrita, Pragmática Textual y Tradiciones Discursivas en la Historiografía Colonial (en los Siglos XVI y XVII). En La Renovación de la Palabra en el Bicentenario de la Argentina. Los Colores de la Mirada Lingüística, editado por Víctor Castel y Liliana Cubo de Severino, pp. 1273-1284. Facultad de Filosofía y Letras Universidad Nacional de Cuyo, Mendoza.

Wachtel, N.

1976. Los Vencidos. Los Indios del Perú frente a la Conquista Española (1530-1570). Alianza, Madrid.

Yupanqui, T.

1992 [1570] Instrucción del Inca Don Diego Titu Cusi Yupanqui para el muy Ilustre señor el Licenciado Lope García de Castro. Pontificia Universidad Católica del Perú, Lima.

Zavala, S.

1994 La Filosofía Política en la Conquista de América. Fondo de Cultura Económica, Santiago. 
Notas

1 Por horizonte de pregunta queremos retomar, principalmente la comprensión hecha por la fenomenología. La noción de horizonte, siguiendo a Husserl, nos permite incorporar un enlace entre la expectativa y la experiencia, ya que "toda experiencia tiene un horizonte experiencial" en tanto una "estructura" que está referida al mundo de la vida como un "margen o estructura co-presente", constituyendo un "mundo de asuntos, de co-datos" (Husserl 1938: 26-38). Para Heidegger la temporalidad funciona como horizonte de cualquier comprensión del ser, donde horizonte equivale a los límites en el marco de la pregunta tanto por el sentido y la existencia (Heidegger 2001: 25-29), como por la temporalidad (historicidad) y la trascendencia del mundo, comprendiendo al concepto de horizonte como unidad extática de la temporalidad (Heidegger 2001: 379-396). La noción de horizonte de pregunta busca fortalecer el alcance de la noción de horizonte como el límite de la totalidad de las cosas dadas, y a la vez como lo que las constituye en cuanto tales (Kuhn 1940: 106-123). Incorporamos a ello la lectura de Ottmar Ette (2013) respecto del horizonte de pregunta (Fragehorizont) como un cuestionamiento relativo a la experiencia (Erfahrung) y también a la vivencia (Erlebnis). El horizonte de pregunta cuestiona y pesquisa, en consecuencia, las posibilidades de análisis, comprensión e interpretación, en este caso referidas a los propios problemas y límites en el pensamiento filosófico de Titu Cusi y Guamán Poma.

2 Es importante reconocer que la noción de categoría se comprende en tanto "percepciones, estereotipos y prácticas culturales, órdenes discursivos" (Martínez 2007: 23) que prefiguran y anteceden (reconfiguran) la construcción e interpretación de sentido que en este caso recorre diferentes modulaciones o momentos acerca de la noción de indio.

3 Es necesario reconocer en el espacio caribeño y mesoamericano instancias anteriores y experimentales en la construcción y la comprensión del concepto de indio en los Andes coloniales (Bernand y Gruzinski 1996).

4 Una filología polilógica se compone de pensamientos e intuiciones que se constituyen desde un "horizonte de pregunta" (Fragehorizont) referido a la profundidad de la relación entre la literatura, la filología y la vida. Esta profundidad es posible comprenderla como "vivencia de la vida" que toma lugar en la literatura y en la filología en tanto expresión vital del acontecer y del sentido de la vivencia no solo desde su carácter existencial (subjetivo), sino que desde su vectorización como un "saber" (Wissen) útil y necesario para la vida (Ette, 2013: 47-70).

5 Historically, peoples who spoke Quechua and Aymara (like other Native South Americans) have long been described as eternal outsiders to the world of letters. Indeed some authors have stereotyped them as "oral" cultures, and assigned to them a role as tragic Rousseauian resisters against alphabetic regimentation. But this is mistaken. The more one reads on the lesser-known archives of the countryside, the more one realizes that much of what we know as Andean culture has grown in and through literacy. If this damages the appeal of the Andean as a "non-Western" culture, so much better. It brings us toward a more realistic encounter with peoples of highland South America, in all their cultural distinctiveness, as actors within the creation of modernity.

6 Es necesario remarcar como antecedente directo de las demandas hechas por los indios de élite andinos a los acuerdos políticos presentados en el congreso regional de San Pedro de Mama. Seguimos lo indicado por Salomon: "Otro ejemplo habría sido la famosa reunión de Mama, de 1562, cuando una asamblea impresionante de kurakas de todo el Perú central acordó con el padre Domingo Santo Tomás en proponer al Consejo de Indias la extinción de las encomiendas a cambio de un autogobierno indígena con considerable gravamen impositivo" (Salomon 2003: 265).

7 Nos referimos a la correspondencia con la Corona hispana entre 1559 y 1565 y particularmente a la capitulación de Acobamba el 24 de agosto de 1566 (Cattan, 2011). Esto significa que Titu Cusi muy probablemente desarrolló altos grados de comprensión y destreza en su relación con los usos del español como idioma jurídico y con la escritura como tecnología de comunicación, lo que complica cualquier acercamiento a los dispositivos y estrategias de enunciaciónpersuasión presentes en su "Instrucción".

8 En el caso de la "Instrucción" de Titu Cusi no podemos olvidar la participación de Martín de Pando (el escribano), fray Marcos García (el traductor), Lope García de Castro (el receptor y representante) y fray Diego de Ortiz (el testigo). Es decir, podemos pensar en un equipo de trabajo, en un taller de elaboración para un manuscrito que adscribe y subvierte los modelos de construcción discursiva occidentales para su propia enunciación (Julien 2006; Cattan 2011).

9 Respecto del Buen Gobierno, sabemos que la segunda parte de la crónica recibe ese título. Durante su exposición Guamán Poma emplea al mismo tiempo una narrativacronológica y un acercamiento descriptivo -en muchos casos vivencial o autoetnográfico (Pratt 1991)- que desmonta las prácticas culturales y las instituciones coloniales. En este sentido sus comentarios e indicaciones respecto del funcionamiento de las instituciones, cargos y personajes coloniales entregan información útil del modo de vida en los Andes coloniales. No obstante, el Buen Gobierno como concepto tiene directa relación con el proyecto civilizatorio occidental mediante el establecimiento de la "policía" y las "letras" (Rama 2004) en los territorios colonizados. Es preciso destacar el sentido y el profundo impacto que el Buen Gobierno guamampino tiene como articulador de un sistema de control político y social alternativo al que se aplicaba en el área andina colonial.

10 El sentido que el sabotaje toma desde la subalternidad, principalmente desde Spivak, es preparativo para una reflexión acerca de cómo pensar dentro/fuera de las polaridades o dicotomías fundamentales como tradición/modernidad, colonial/postcolonial, Occidente/Oriente, entre otras. Spivak habla de un sabotaje afirmativo (affirmative sabotage), a fin de determinar una aparente contemporaneidad (entre tradición/ modernidad) que no puede ser advertida si se piensa dicotómicamente. Spivak insiste en un doble vínculo (double bind) que permitiría soslayar el pensar dicotómico estableciendo la necesidad de enfrentar y crear una epistemología alternativa (Spivak 2012: 1-34). 
